\title{
Evaluation of Residential Environment Adaptability for the Elderly in the Shantytown Reconstruction
}

\author{
Yuliang Yan ${ }^{1, *}$, Dake Wei ${ }^{1,2}$ \\ ${ }^{1}$ Academy of Architecture, Harbin Institute of Technology, Harbin, China \\ ${ }^{2}$ Key Laboratory of Human Settlement Environment Science in Cold Areas of Heilongjiang Province, Harbin, China \\ Email address: \\ 969679047@qq.com (Yuliang Yan),wdk_hit@126.com (Dake Wei) \\ *Corresponding author
}

\section{To cite this article:}

Yuliang Yan, Dake Wei. Evaluation of Residential Environment Adaptability for the Elderly in the Shantytown Reconstruction. Science Discovery. Vol. 7, No. 5, 2019, pp. 299-305. doi: 10.11648/j.sd.20190705.17

Received: September 10, 2019; Accepted: October 21, 2019; Published: October 23, 2019

\begin{abstract}
Objectives: The aim of this study is to assess the elderly-oriented physical environment of shantytown reconstruction.Background: Over the past decade, it has vigorously promoted the shantytown reconstruction projects in China.As it shows that the proportion of the "empty nest" elderly with low income in the relocated residents is relatively much higher, and the extent to the elderly-oriented physical environment of shantytown reconstruction remains to be further studied. As the LESE-ILE scale is an evaluation model with multiple targets, dual-scale and variable weight, which aims at the constituent elements of the living system, the elderly living independently. Methods:Taking 3 communities in the south of Baotou Beiliang New District as an example, the paper introduces LESE-ILE scale as an evaluation to get a objective fraction in elderly-oriented physical environment, and combines semi-open interviews with elderly residents to carry out an evaluation study on the adaptability for the elderly of physical environment in the new shantytown reconstruction area.Results:Quantitatively evaluates in 4 domains: residential buildings, community supporting facilities, community service network, urban functional support and other environmental dimensions in Beiliang New District. The elderly-oriented physical environment has been greatly improved with the fraction reaching the level of the general residential system. The indoor physical environment is relatively perfect, however, the supporting facilities and service network in the community need to be strengthened. It remains to be improved the poor urban service support function due to being on the edge of the city in the future.Conclusions: The paper analyses the results evaluated from the LESE-ILE scale and puts forward the improvement strategies for the aging design in the shantytown modification and construction projects to improve the elderly-oriented physical environment. The paper also supplies a feedback and demonstration for the better of the LESE-ILE evaluation scale.
\end{abstract}

Keywords: Shantytown Reconstruction, Physical Environment, Elderly-oriented, LESE-ILE Evaluation Scale

\section{棚改新区居住环境适老性评价研究}

间玉梁 ${ }^{*}$ ，卫大可 ${ }^{1,2}$

1哈尔滨工业大学建筑学院, 哈尔滨, 中国

2 黑龙江省寒地城乡人居环境科学重点实验室, 哈尔滨, 中国

邮箱

969679047@qq.com（闵玉梁）,wdk_hit@126.com（卫大可）

摘要：近十年来，我国大力推进棚户区改造建设，一批棚改新区相继建成。调查表明，回迁居民中低收入“空巢”老人 占比较高, 而居住环境能多大程度满足老年人的独立生活需求, 有待进一步研究。本文以包头市北梁新区南区的三个 社区为例, 引入LESE-ILE量表作为评价工具, 并结合老年住户的半开放式访谈, 开展棚改新区居住环境的适老性评价 
研究。定量评价了北梁新区的居住建筑、社区配套设施、社区服务网络、城市功能支持等环境维度的适老化程度; 分 析评价结论，为新的棚改工程的适老化设计提出改进策略；并对LESE-ILE量表进行证实反馈。

关键词: 棚改新区, 居住环境, 适老性评价, LESE-ILE量表

\section{1. 研究背景}

\section{1. 国家棚户区改造工程的大力推进}

《国务院关于加快棚户区改造工作的意见》中指 出:“棚户区改造是重大的民生工程和发展工程, 其目的是 为了有效改善困难群众住房条件, 缓解城市内部二元矛盾, 提升城镇综合承载能力, 促进经济增长与社会和谐。”[1] 从2015年开始, 我国实施了棚改三年计划以来, 2015至 2017年完成棚户区改造 1800 万套。2017年5月国务院常务 会议已经决定，2018年～2020年将改造各类棚户区 1500 万套。[4]北梁棚户区曾经是包头市面积最大, 人居条件差, 社会弱势群体多，市政基础设施严重圆乏的棚户区。2013 年全面启动了棚改工程, 截止到2014年10月底, 拆迁安置 工作全面告捷, 累计征收安置居民 5.36 万户 10.9 万人, 拆除房屋面积430万平方米。[3]

\section{2. 棚户区居民多为“空巢”老人}

我国现在是世界上老年人口数量最多的国家。居民居 住观念渐渐发生了改变, 依托子女的传统家庭养老模式逐 步瓦解, 在广大的城市和农村地区, 老年人独立居住、独 立生活的情况变得相当普遍。[2]由于棚户区居住的人群多 是低收入人群, 家庭内的子女多外出务工, 因而棚户区回 迁的居民多为“空巢”老人, 即拥有自己的生活方式; 拥有 自理或半自理的健康水平; 拥有维持生活的经济来源; 独 立居住的老年人。

\section{3. 棚改新区缺乏定量的适老性评价}

棚改新区的安置房屋性质多为经济适用住房、廉租住 房和公共租赁住房。为了控制成本, 安置新区一般仅按国 家底线标准建设, 居住环境能多大程度满足老年人独立生 活的需求, 即在居住建筑、社区配套设施、社区化服务网 络及城市功能支持方面的考量, 我国还暂时缺乏进一步的 定量适老性评价研究。

\section{2. 评价及研究方法}

\section{1. 评价对象}

包头市北梁新区南区的三个社区: 崟光社区、南嘉园 社区、安居社区

\section{2. 评价工具}

LESE-ILE量表评价工具。该量表评价包含居住环境、 社区配套设施、社区服务网络、城市功能支持等环境维度 的适老化程度评价与打分。依据国内大中小不同等级的独
立生活老年人的生活需求与环境需求, 结合国内外现有评 价量表的框架形式与评价维度所形成的完整的独立生活 老年人居住系统评价量表。量表的横向维度为老年人的通 用需求与专用需求, 其中通用需求包括: 尊严和隐私、舒 适性、自理以及社交需求; 专用需求包括: 可达性、物理 支持、感观支持以及安全需求。量表的纵向内容就是具体 的评价条目。评价条目中中包含控制项与优选项, 控制项 为独立生活老年人生活的必要条目, 为评价居住系统是否 满足老年人最基本的生活需求; 优选项和控制项所有条目 组成完整的居住系统评价条目, 用于完整评价。[6]

\section{3. 研究方法}

通过对社区各种类型空间的实地调研的客观情况以 及对社区管理人员的访谈结果对LESE-ILE量表的各项评 价条目进行评测。由于LESE-ILE量表着重于老年人居住 环境, 评价的方向更加偏向于实体环境的评价, 没有直接 将建筑的因素直接与老年人的生活满意程度联系起来, 而 是一些能满足老年人需求的实际要素, 因此本文在评价结 果的配合了老年人对居住环境的满意程度及改造愿景调 查来补充证明LESE-ILE量表评价的结果。[5,8,15-17]

通过随机抽样、半开放式访谈以及现场填写调查问卷 的方法对北梁新区南区的三个社区的72位老年居民进行 了居民基本情况、居住环境满意度及改造愿景的调查。其 中居民基本情况包含性别、年龄、文化程度、居住情况、 身体情况和经济情况等方面。居住环境满意度包含与 LESE-ILE量表相关的居住环境、社区配套设施、社区服 务网络、城市功能支持四方面满意度的调查。改造愿景包 括居民对于现居住地区不足之处的改善意愿与希望配备 的设施。 $[7,10,12]$

\section{3. 评价结果与分析}

\section{1. 社区概况}

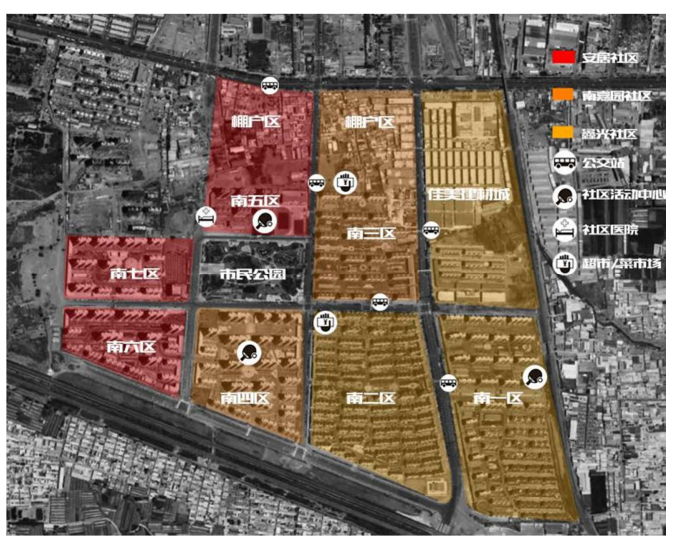

图1 北梁新区南区相关设施分布（作者自绘）。 
包头市北梁新区南区设有一个社区医院、一所小学, 一所幼儿园, 一个市民广场以及一家超市, 服务于三个社 区。南区各项老年设施及社区居委分布如 (图1) 所示。

金光社区包括南一区、南二区两个住宅小区，共计 134栋住宅楼, 入住居民11028户, 共计 17390 人, 60 岁以 上老年人 1664 人, 占 $9.57 \%$, 两个卫生服务站, 一个老年 活动中心。南嘉园社区包括南三区、南四区两个住宅小 区, 共计47栋住宅楼, 入住居民5388户, 共计 8496 人, 60 岁以上老年人 745 人, 占 $8.77 \%$, 设有一个卫生服务站, 一所老年大学及一个老年活动中心。安居社区包括南五 区、南六区、南七区三个住宅小区, 共计36栋住宅楼, 入住居民4676户, 共计 11672 人, 其中 60 岁以上老年人 968
人, 占 $8.29 \%$, 设有一个卫生服务站, 一所老年大学及一 个老年活动中心。

\subsection{LESE-ILE量表评价结果及发现的问题}

\subsection{1. 整体评分}

LESE-ILE量表最终结果采用百分制计算, 因此可以 利用分等级的方式对评价的居住系统的状态做一个划分。 总得分 $>60$ 分, 为基本达标居住系统; 总得分 $>70$ 分, 为一 般居住系统; 总得分 $>80$ 分, 为良好居住系统; 总得分 $>90$ 分, 为优秀居住系统。北梁新区南区居住系统构成维度和 老年人需求维度分别为 69.1 分和 66.7 分因而北梁新区南区 基本达标居住系统，居住环境基本符合老年人的需求。如 (表1）所示。

表1 居住系统评价结果。

\begin{tabular}{|c|c|c|c|c|c|c|c|}
\hline \multirow{2}{*}{\multicolumn{3}{|c|}{$\begin{array}{l}\text { 评价条目基本要素及权重(\%)评价维度 } \\
\text { 及权重 }(\%)\end{array}$}} & \multirow{2}{*}{$\begin{array}{l}\text { 居住建筑项 } \\
34.54\end{array}$} & \multirow{2}{*}{$\begin{array}{l}\text { 社区配套设施项 } \\
30.86 \\
\end{array}$} & \multirow{2}{*}{$\begin{array}{l}\text { 城市化服务网络项 } \\
20.92\end{array}$} & \multirow{2}{*}{$\begin{array}{l}\text { 城市功能支持项 } \\
13.68\end{array}$} & \multirow{2}{*}{ 加权总得分 } \\
\hline & & & & & & & \\
\hline 通 & 尊严和隐私需求 & 11.64 & $0(2)$ & $1(1)$ & $1(1)$ & $0(0)$ & \multirow{8}{*}{$\begin{array}{l}66.7 \text { (居住建筑维度) } \\
69.11 \text { (老年人需求维 } \\
\text { 度) }\end{array}$} \\
\hline 用 & 舒适性需求 & 16.45 & $28(42)$ & $5(9)$ & $1(4)$ & $0(0)$ & \\
\hline 需 & 自理需求 & 21.25 & $6(10)$ & $16(29)$ & $6(11)$ & $2(5)$ & \\
\hline 求 & 社交需求 & 8.36 & $0(0)$ & $2(3)$ & $2(3)$ & $0(2)$ & \\
\hline 专 & 可达性需求 & 7.26 & $5(19)$ & $11(30)$ & $4(6)$ & $7(10)$ & \\
\hline 用 & 物理支持需求 & 6.11 & $22(49)$ & $2(7)$ & $1(4)$ & $1(3)$ & \\
\hline 需 & 感官支持需求 & 4.23 & $4(11)$ & $6(7)$ & $0(1)$ & $0(1)$ & \\
\hline 求 & 安全需求 & 24.70 & $25(50)$ & $7(10)$ & $5(19)$ & 0 (1) & \\
\hline
\end{tabular}

\subsection{2. 居住环境}

量表对公共走廊、建筑出入口、楼梯和电梯、卧室和起居室、卫生间、懕房、阳台/露台、过道和储藏空间 8 个居 住环境空间进行了 44项控制项目, 127项优选项目的评价。评价结果如（表2）所示。

表2 居住建筑项得分总表。

\begin{tabular}{|c|c|c|c|c|c|c|c|c|c|c|c|}
\hline \multirow{2}{*}{\multicolumn{2}{|c|}{ 居住建筑项得分总表 }} & \multicolumn{3}{|c|}{ 公共空间 } & \multicolumn{5}{|c|}{ 套内空间 } & \multirow[b]{2}{*}{$\begin{array}{l}\text { 实际得分 } \\
\text { 个数 (/个) }\end{array}$} & \multirow[b]{2}{*}{$\begin{array}{l}\text { 理想得分 } \\
\text { 个数 (/个) }\end{array}$} \\
\hline & & $\begin{array}{l}\text { 公共走 } \\
\text { 廊 }\end{array}$ & $\begin{array}{l}\text { 建筑出 } \\
\text { 入口ロ }\end{array}$ & $\begin{array}{l}\text { 楼梯和 } \\
\text { 电梯 }\end{array}$ & $\begin{array}{l}\text { 卧室和 } \\
\text { 起居室 }\end{array}$ & 卫生间 & 厨房 & $\begin{array}{l}\text { 阳台和 } \\
\text { 露台 }\end{array}$ & $\begin{array}{l}\text { 过道和储藏 } \\
\text { 空间 }\end{array}$ & & \\
\hline 通 & 尊严和隐私需求 & 0 & 1 & 0 & 0 & 0 & 0 & 0 & 0 & 1 & 2 \\
\hline 用 & 舒适性需求 & 0 & 3 & 4 & 8 & 8 & 6 & 0 & 4 & 33 & 43 \\
\hline 需 & 自理需求 & 0 & 0 & 0 & 1 & 4 & 3 & 0 & 1 & 9 & 10 \\
\hline 求 & 社交需求 & 0 & 1 & 0 & 0 & 0 & 0 & 0 & 0 & 1 & 1 \\
\hline 专 & 可达性需求 & 3 & 2 & 2 & 2 & 3 & 2 & 2 & 2 & 16 & 22 \\
\hline 用 & 物理支持需求 & 0 & 2 & 1 & 4 & 7 & 5 & 0 & 6 & 25 & 48 \\
\hline 需 & 感官支持需求 & 1 & 1 & 4 & 1 & 2 & 1 & 0 & 0 & 10 & 17 \\
\hline 求 & 安全需求 & 3 & 6 & 9 & 6 & 4 & 7 & 1 & 3 & 38 & 55 \\
\hline
\end{tabular}

居住环境整体而言设施相对完整, 均能保证主卧和起 居室光照充足，部分户型可以保证两个卧室均朝南向; 可 以保证正常通风和冬季保温。但是对于老年人使用的便利 性方面有待加强, 缺少对于老年人的特殊关怀。例如, 卫
生间没有预留直径不小于 $1.5 \mathrm{~m}$ 的轮椅回转空间或 $\mathrm{L}$ 型流线 回转空间; 卫生间多设置为内开门; 在坐便器、洗浴器、 盃洗盆旁未配备扶手及预留空间; 卧室和卫生间未配备紧 急求助报警装置等。室内环境如（图2）所示。
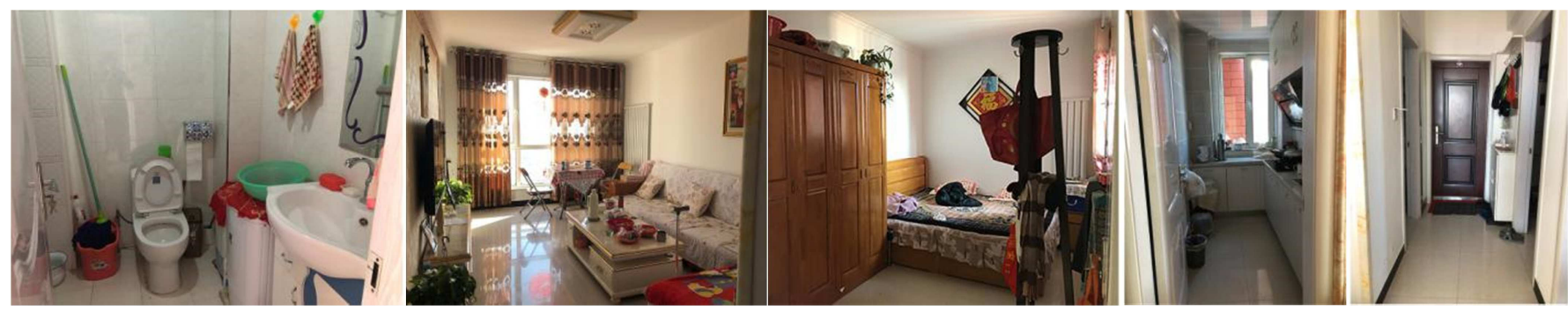

图2 室内居住环境（作者自摄）。 


\subsection{3. 社区配套设施}

量表对体育设施、医疗服务设施、管理设施、服务设施、商业设施、福利设施、文化教育设施7个社区配套设施进 行了61项控制项目，39项优选项目的评价。评价结果如（表3）所示。

表3 社区设施环境得分总表。

\begin{tabular}{|c|c|c|c|c|c|c|c|c|c|c|}
\hline \multirow{2}{*}{\multicolumn{2}{|c|}{$\begin{array}{l}\text { 社区配套设施项 } \\
\text { 得分总表 }\end{array}$}} & \multicolumn{7}{|c|}{ 社区配套设施 } & \multirow[b]{2}{*}{$\begin{array}{l}\text { 实际得分 } \\
\text { 个数 (/个) }\end{array}$} & \multirow[b]{2}{*}{$\begin{array}{l}\text { 理想得分 } \\
\text { 个数 (/个) }\end{array}$} \\
\hline & & $\begin{array}{l}\text { 体育设 } \\
\text { 施 }\end{array}$ & $\begin{array}{l}\text { 医疗服 } \\
\text { 务设施 }\end{array}$ & $\begin{array}{l}\text { 管理设 } \\
\text { 施 }\end{array}$ & $\begin{array}{l}\text { 服务设 } \\
\text { 施 }\end{array}$ & $\begin{array}{l}\text { 商业设 } \\
\text { 施 }\end{array}$ & $\begin{array}{l}\text { 福利设 } \\
\text { 施 }\end{array}$ & $\begin{array}{l}\text { 文化教 } \\
\text { 育设施 }\end{array}$ & & \\
\hline \multirow{4}{*}{ 通用需求 } & 尊严和隐私需求 & 0 & 1 & 0 & 0 & 0 & 0 & 0 & 1 & 1 \\
\hline & 舒适性需求 & 1 & 3 & 1 & 0 & 1 & 2 & 0 & 8 & 9 \\
\hline & 自理需求 & 6 & 4 & 2 & 3 & 4 & 4 & 3 & 26 & 30 \\
\hline & 社交需求 & 2 & 0 & 0 & 0 & 0 & 1 & 0 & 3 & 3 \\
\hline \multirow{4}{*}{ 专用需求 } & 可达性需求 & 4 & 7 & 6 & 4 & 7 & 4 & 4 & 36 & 51 \\
\hline & 物理支持需求 & 3 & 4 & 3 & 3 & 3 & 3 & 3 & 22 & 28 \\
\hline & 感官支持需求 & 0 & 1 & 1 & 1 & 1 & 1 & 1 & 6 & 7 \\
\hline & 安全需求 & 2 & 1 & 2 & 1 & 1 & 1 & 1 & 9 & 10 \\
\hline
\end{tabular}

社区配备相对完善。有方便老年人到达的社区居委会 用房以及党政服务大厅。方便社区老年人使用的生活服务 用房、保健康复用房、娱乐用房等休闲设施。周边配备集 中商业设施以及菜市场, 但是对于部分住宅小区, 腿脚稍 有不便的老年人而言距离略远, 出行采购会有困难。配备 有老年大学, 以及专门供老年人使用的文化图书用房和课 堂用房, 但是课程相对单一, 授课人员稀少。存在功能用 房使用率低, 缺乏服务管理的问题。在各类设施中均缺少 无障碍卫生间, 部分活动室布置在二楼及以上的楼层, 但 并没有设置电梯或无障碍坡道, 设施中未配备完善、清晰、 醒目的标识系统。

\subsection{4. 社区化服务网络}

量表对公共交通网络、市政设施网络、老年人监控网 络、紧急救助网络、通信系统网络、养老信息服务网络6 项社区化服务网络进行了 6 项控制项目, 24项优选项目的 评价。评价结果如 (表4) 所示。

服务网络设置相对单一。每个社区均在主要街道设有 监控网络, 但是没有配备居住建筑内部的老年人监控系统; 暂时缺乏老年人紧急呼叫设施; 通信系统网络完善; 缺乏 提供生活照料服务的网络预约平台以及提供养老转介平 台，接入各类养老机构的养老信息服务网络。

表4 社区化服务网络项得分总表。

\begin{tabular}{|c|c|c|c|c|c|c|c|c|c|}
\hline \multirow{2}{*}{\multicolumn{2}{|c|}{$\begin{array}{l}\text { 社区化网络服务项 } \\
\text { 得分总表 }\end{array}$}} & \multicolumn{6}{|c|}{ 社区化网络服务 } & \multirow{2}{*}{$\begin{array}{l}\text { 实际得分 } \\
\text { 个数 (/个) }\end{array}$} & \multirow{2}{*}{$\begin{array}{l}\text { 理想得分 } \\
\text { 个数 (/个) }\end{array}$} \\
\hline & & $\begin{array}{l}\text { 公共交通网 } \\
\text { 络 }\end{array}$ & $\begin{array}{l}\text { 市政设 } \\
\text { 施网络 }\end{array}$ & $\begin{array}{l}\text { 老年人监控网 } \\
\text { 络 }\end{array}$ & $\begin{array}{l}\text { 紧急救 } \\
\text { 助网络 }\end{array}$ & $\begin{array}{l}\text { 通信系 } \\
\text { 统网络 }\end{array}$ & $\begin{array}{l}\text { 养老信息 } \\
\text { 服务网络 }\end{array}$ & & \\
\hline \multirow{4}{*}{$\begin{array}{l}\text { 通用 } \\
\text { 需求 }\end{array}$} & 尊严和隐私需求 & 0 & 1 & 0 & 0 & 0 & 0 & 1 & 1 \\
\hline & 舒适性需求 & 3 & 1 & 0 & 0 & 0 & 0 & 4 & 6 \\
\hline & 自理需求 & 1 & 0 & 0 & 0 & 0 & 0 & 1 & 7 \\
\hline & 社交需求 & 0 & 0 & 0 & 0 & 0 & 0 & 0 & 2 \\
\hline \multirow{4}{*}{$\begin{array}{l}\text { 专用 } \\
\text { 需求 }\end{array}$} & 可达性需求 & 2 & 1 & 0 & 0 & 0 & 0 & 3 & 6 \\
\hline & 物理支持需求 & 0 & 2 & 0 & 0 & 0 & 0 & 2 & 5 \\
\hline & 感官支持需求 & 1 & 0 & 0 & 0 & 0 & 0 & 1 & 2 \\
\hline & 安全需求 & 3 & 1 & 0 & 3 & 0 & 0 & 7 & 3 \\
\hline
\end{tabular}

\subsection{5. 城市功能支持}

量表对出行交通支持、休闲娱乐空间支持、购物支持、对社区内的支持4项城市功能支持进行了 8 项控制项目， 7 项优选项目的评价。评价结果如（表5) 所示。

表5 城市功能支持项得分总表。

\begin{tabular}{|c|c|c|c|c|c|c|c|}
\hline \multirow{2}{*}{\multicolumn{2}{|c|}{ 城市功能支持项得分总表 }} & \multicolumn{4}{|l|}{ 城市功能支持 } & \multirow{2}{*}{$\begin{array}{l}\text { 实际得分 } \\
\text { 个数 (/个) }\end{array}$} & \multirow{2}{*}{$\begin{array}{l}\text { 理想得分 } \\
\text { 个数 (/个) }\end{array}$} \\
\hline & & 出行交通支持 & 休闲娱乐空间支持 & 购物支持 & 对社区内支持 & & \\
\hline \multirow{4}{*}{ 通用需求 } & 尊严和隐私需求 & 0 & 0 & 0 & 0 & 0 & 0 \\
\hline & 舒适性需求 & 0 & 0 & 0 & 0 & 0 & 0 \\
\hline & 自理需求 & 0 & 1 & 0 & 0 & 1 & 4 \\
\hline & 社交需求 & 0 & 0 & 0 & 0 & 0 & 1 \\
\hline \multirow{4}{*}{ 专用需求 } & 可达性需求 & 1 & 2 & 0 & 0 & 3 & 9 \\
\hline & 物理支持需求 & 0 & 2 & 0 & 0 & 2 & 3 \\
\hline & 感官支持需求 & 0 & 0 & 0 & 0 & 0 & 1 \\
\hline & 安全需求 & 0 & 0 & 0 & 0 & 0 & 1 \\
\hline
\end{tabular}


整个南区配备 5 个公交出行站点, 分布集中, 位置比 较偏远。社区医院分布在最北端, 对于南部的居民距离相 对较远, 社区外医院或卫生所会提供上门体检服务。社区 内部缺乏近距离公共出行的棋牌室、剧院、茶楼等老年人 常去场所。

由于北梁新区整体位于包头市东河区最东段, 建成时 间相对较短, 整个区域还处于建设完善阶段, 城市的各项 功能设施还在规划开发中, 因而居住系统的城市功能支持 相对欠缺。加之棚户区改造工程就业安置难的问题，很多 居民在之前仅仅依靠自有房屋开展生活, 依靠小买卖维持 生计, 于是, 便出现很多开在住宅楼内的餐馆、超市、小 诊所等等无照经营的私营场所, 这虽然解决了在此居住的
老年人购物难, 出行难的问题, 但这并非是长久之计和合 法之为, 也加大了物业管理的难度。

\section{3. 老年居民对居住环境满意度调查情况}

参与调查的 72 位老年人中, 均无精神病及明显的记忆 与智力损害, 能回答调查问卷的各项问题并同意参与该项 研究。其本情况如 (表6) 所示。对目前的整体居住环境、 居住环境、社区配套设施、社区服务网络、城市功能支持 四方面的满意度情况如 (表7) 所示。

根据调查结果可知, LESE-ILE量表的结果与老年人 的满意度情况基本一致, 均在居住建筑、社区配套设施方 面得分较高, 在社区化服务网络与城市功能支持方面需要 进一步加强与改善。

表6 居民基本情况。

\begin{tabular}{llll}
\hline 性别 & 年龄 & 文化程度 & 自理情况 \\
\hline 男性: $73.6 \%$ (53人) & $60-69$ 岁: $26.3 \%$ (19人) & 初中以下: $6.9 \%$ (5人) & 行动无困难: $91.7 \%$ (66人) \\
女性: $26.4 \%$ 与配偶居住: $95.8 \%$ (69人) \\
\end{tabular}

表7 居民满意度与改建意愿调查统计。

\begin{tabular}{|c|c|c|c|c|c|}
\hline 整体满意度 & 居住环境 & & 社区配套设施 & 社区化服务网络 & 城市功能支持 \\
\hline $\begin{array}{l}\text { 非常满意: } \\
94.4 \% \\
\text { (68人) }\end{array}$ & $\begin{array}{l}\text { 出入口行动不方 } \\
\text { 便: } 20.8 \% \\
\text { (15人) }\end{array}$ & $\begin{array}{l}\text { 卧室和起居室行 } \\
\text { 动不方便: } 4.2 \% \\
\text { (3人) }\end{array}$ & $\begin{array}{l}\text { 便民服务设施不完善: } \\
9.7 \% \\
\text { (7人) }\end{array}$ & $\begin{array}{l}\text { 出行方便的道路系统不 } \\
\text { 完善: } 9.7 \% \text { ( } 7 \text { 人) }\end{array}$ & $\begin{array}{l}\text { 缺乏出行方便的公交系统: } \\
62.5 \% \text { (45人) }\end{array}$ \\
\hline $\begin{array}{l}\text { 基本满意: } 5.6 \% \\
\text { (4人) }\end{array}$ & $\begin{array}{l}\text { 入户楼梯和电梯 } \\
\text { 行动不便: } 0 \\
\text { (0人) }\end{array}$ & $\begin{array}{l}\text { 卫生间行动不方 } \\
\text { 便: } 11.2 \% \\
\text { (8人) }\end{array}$ & $\begin{array}{l}\text { 商业设施不完善: } 15.2 \% \\
\text { (11人) }\end{array}$ & $\begin{array}{l}\text { 老年人安全监控系统不 } \\
\text { 完善: } 29.2 \% \text { (21人) }\end{array}$ & $\begin{array}{l}\text { 缺乏小区周围的休闲娱乐活动 } \\
\text { 场所: } 13.9 \% \text { (10人) }\end{array}$ \\
\hline $\begin{array}{l}\text { 不满意: } 0 \\
\text { (0人) }\end{array}$ & $\begin{array}{l}\text { 宅间走道行动不 } \\
\text { 方便: } 6.9 \% \\
\text { (5人) }\end{array}$ & $\begin{array}{l}\text { 厨房行动不方便: } \\
6.9 \% \text { (5人) }\end{array}$ & $\begin{array}{l}\text { 福利设施不完善： } 2.7 \% \\
\text { (2人) }\end{array}$ & $\begin{array}{l}\text { 紧急求助网络不完善: } \\
44.4 \% \text { (32人) }\end{array}$ & $\begin{array}{l}\text { 缺乏方便到达的购物场所: } \\
29.2 \% \text { (21人) }\end{array}$ \\
\hline \multirow[t]{3}{*}{$\begin{array}{l}\text { 非常不满意:0 } \\
\text { (0人) }\end{array}$} & $\begin{array}{l}\text { 宅间公共空地行 } \\
\text { 动不方便: } 0 \\
\text { (0人) }\end{array}$ & $\begin{array}{l}\text { 阳台和露台行动 } \\
\text { 不方便: } 0 \text { (0人) }\end{array}$ & $\begin{array}{l}\text { 文化教育设施不完善: } \\
13.9 \% \\
(10 \text { 人) }\end{array}$ & $\begin{array}{l}\text { 通讯系统不完善: } 0 （ 0 \\
\text { 人） }\end{array}$ & \multirow[t]{3}{*}{$\begin{array}{l}\text { 缺乏社区机构提供上门服务: } \\
20.8 \% \text { (15人) }\end{array}$} \\
\hline & $\begin{array}{l}\text { 都很方便: } 72.3 \% \\
\text { (52人) }\end{array}$ & $\begin{array}{l}\text { 过道和储存空间 } \\
\text { 行动不方便: } \\
4.2 \% \text { (3人) }\end{array}$ & $\begin{array}{l}\text { 都很完善: } 58.5 \% \\
\text { (42人) }\end{array}$ & $\begin{array}{l}\text { 养老信息服务平台不完 } \\
\text { 善: } 48.6 \% \text { (35人) }\end{array}$ & \\
\hline & & $\begin{array}{l}\text { 都很方便: } 73.5 \% \\
\text { ( } 53 \text { 人) }\end{array}$ & & $\begin{array}{l}\text { 周全的环境配套市政设 } \\
\text { 施不完善: } 25 \% \text { (18人) }\end{array}$ & \\
\hline
\end{tabular}

\section{4. 棚户区改造工程适老性设计启示}

分析LESE-ILE量表评价结果以及社区老年居民满意 度和改造愿景调查的结果, 提出对于棚户区改造工程的适 老性设计策略。

\section{1. 保证可达性安全性的整体规划}

日常休闲场所、服务设施、户外活动场地等与老年人 息息相关的空间对于老年人的户外行为至关重要, 因此需 要保证其可达性以及安全性。[13]中心广场适宜布置住宅 区域的中心位置, 并配置健步道、健身器械、休㓤设施, 方便老年人的日常健体活动, 保证公交站下有充足的等待 空间, 并设置休息座椅。公交站应分散布置, 尽量减少居 住区入口与公交站之间的距离。道路规划时, 要保证人车 分离。由于老年人视力和体力的弱化, 断头路会使老年人 徒增路程, 因而要尽量避免断头路的出现。路面停车区域
尽量远离老年人活动场地。在道路系统设计中, 最好多条 途径可以到达目的地。

\section{2. 提供充满特殊关怀的无障碍设计}

由于老年人生理和心理特征以及对可达性和安全性的 特殊需求, 居住系统内的无障碍设计, 是整体适老性设计的 重要设计点, $[11,13]$ 由于受建筑空间条件限制和开发成本的 限制, 导致无障碍设施不足, 对于老年人的日常生活会很不 方便, 反而适得其反, 也会对整体适老性评价结果影响很大。 例如, 安居社区的住宅单元出入口的未设置扶手的无障碍坡 道, 虽然有考虑无障碍设计, 但实际并未考量到老年人的实 际需求, 大多数行动不便的老年人会出于没有扶手的坡道不 安的心理, 选择难以行走的踏步。如（图3a）。

\section{3. 保证合理的空间与尺度}

老年人的行为具有特殊性, 与年轻人不同, 需要保证 合理适宜的空间尺度。[9]例如, 由于老人在进行如则、更 
衣等行为时需要较长的时间和充足的空间, 卫生间与过道 需要预留直径不小于 $1.5 \mathrm{~m}$ 的轮椅回转空间或 $\mathrm{L}$ 型流线回转 空间。因为老年人的腹部会比较大, 侧身行走的动作对于 他们而言会很难, 因此住宅小区的人行出入口应尽量避免 为了限流的过窄通道, 如(图3b)。

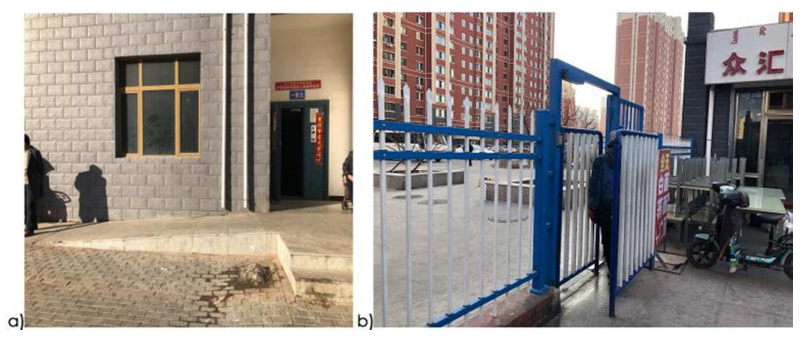

图3 北梁社区出入口现状（作者自摄）。

\section{4. 结合智能化养老系统}

智能养老是一种现代养老模式, 它是将现代通信与信 息技术、无线传感网络、计算机网络技术与老年服务行业 技术和智能控制技术相结合, 该系统能为老年人提供一种 安全便捷和健康舒适服务。[9]面对我国日益严重的人口老 龄化, “空巢老人”逐年增加的国情, 推行智能化养老必将 成为老年人服务行业的一个发展方向。例如: 增设便于老 年人操作和识别的室内外安全警报系统、能提高使用便利 性的导视系统; 建立紧急救助网络, 当老年人发生突发疾 病、跌倒等情况时, 可以与社区周边消防、疾控、医院或 者子女立即产生联系取得帮助; 通过布置在室内以及公共 区域的传感器, 完成对环境的检测, 利用收集来的测量参 数对老年人的日常生活起居、室外活动进行相应的指导。

\section{5.结语}

运用LESE-ILE量表对包头市北梁棚户区改造新区南 区的三个社区的评价, 可以得出以下结果: 该居住系统构 成维度和老年人需求维度分别为 69.1 分和 66.7 分, 基本达 标居住系统, 居住环境基本满足居住老年人的需求。在居 住建筑和社区配套设施方面配备完善, 在社区化服务网络 和城市功能支持方面配备略显单一, 有待改进提高。通过 量表评价结果与老年居民的调查结果, 总结出棚户区改造 工程适老性设计启示: 保证可达性安全性的整体规划、提 供充满特殊关怀的无障碍设计、保证合理的空间与尺度、 结合智能化养老系统。

本次评价研究中, 由于人力物力资源有限, 因此调查 的老年人样本数量不尽理想, 因此在后续的研究中会加大 调查样本的数量, 保证研究的完整性和严谨性。其次, 由 于住宅属于私人领域, 无法在室内停留时间过长, 并且该 维度下的评价条目相对较多, 因此可能对于居住建筑维度 下的评价略有误差。在后续的调查中将协调有关部门加长 对于室内环境的调研时长, 同时利用网络资源, 弥补该项 研究的局限性。

通过本次的实地评测, 对LESE-ILE量表有了一次实证, 得到了实际运用上的反馈。为之后的量表精简优化提供了 北方地区棚户区改造案例的样本支持。同时，对于老年人
的走访调查, 也为后来的数据分析提供了辅助支持。为城 市社区居住环境适老性评价标准的建立提供了样本支持。

后续的研究将在对我国各地区的社区科学系统进行 分类的基础上, 在全国范围内, 选取典型的的、覆盖类型 面广泛的社区作为城市社区居住环境适老性的评价对象。 运用LESE-ILE量表对选定社区的老年人居住环境进行应 用评价。在对社区居住环境评价的同时, 参照世界卫生组 织开发的生存质量评价量表以及由迪纳( Diener) 创制生 活满意度量表来测量编制社区老年人生活满意度量表, 测 量老年人的生活质量。通过评价与测量, 为后续的研究提 供数据的支撑。通过主成分分析和相关性分析等数理统计 的方法对LESE-ILE量表进行进一步的优化，以建立城市 社区居住环境适老性评价标准。

\section{致谢}

本文为国家自然科学基金项目《居家养老模式下独立 生活老年人居住系统构建研究》(51678175), 以及黑龙江省 科学基金（E2018029）的阶段性成果之一。

\section{参考文献}

[1] 国务院关于进一步做好城镇棚户区和城乡改造及配套基础 设施有关工作的意见 http://www.gov.cn/zhengce/content/2015-06/30/content_9991. htm.

[2] 中国产业信息. 2017 年中国人口老龄化现状分析及发展趋 势 预 测 [EB/OL]. [2016-09-20]. http://www.chyxx.com/industry/201609/449915.html.

[3] 景志铮.城市棚改新区居民的社区融入研究——基于内蒙 古包头市北梁棚改居民的调查 [J]. 社会科学研 究,2018(04):95-102.

[4] 战越. 基于养老需求的哈尔滨棚户区改造的适老性设计研 究[D].东北林业大学, 2016 .

[5] 邱迪,白旭.“城市社区住宅适老性评价体系”应用初探— 以昆明市为例[J].价值工程,2015,34(36):1-6.

[6] 徐星. 独立生活老年人居住系统评价量表构建研究[D].哈 尔滨工业大学,2018.

[7]曲嘉瑶.城市居住环境对老年人生活质量的影响一以北 京市为例 [J].城市问题,2018(12):44-54.

[8] 曲嘉瑶.城市老年居住环境评价量表编制研究——基于北 京市的实证调查[J].老龄科学研究,2017,5(12):3-17.

[9] 李炜,黄雯.适老性住区一未来养老居住的重要发展方向 [J].中外建筑,2015(09):41-44.

[10] 安浩元. 城市社区住宅适老性评价体系研究[D].天津大 学, 2012 .

[11] 王小荣,王晶.浅谈在居家养老概念下既有居住社区环境的 适老性改造更新[J]. 建筑与文化,2015(03):116-117. 
[12] 王小荣,贾巍杨.社区养老实态调研与满意度评价指标初探 [J].建筑学报,2014(S2):157-159.

[13] 曲翠萃,王小荣,袁逸倩,张旭.基于行为需求的天津适老性社 区室外环境设计策略[J].建筑与文化,2014(12):98-99.

[14] 王小荣,曲翠萃.基于问卷调研的适老性社区设计方向探索 [J].建筑与文化,2014(05):82-84.

[15] 原婕. 探索居家养老趋势下社区公共环境体系的再构建[D]. 天津大学,2017
[16] Parker, Sarah Barnes, Kevin Mckee. Quality of life and building design in residential and nursing homes for older people [M]. Society· November, 2004.

[17] Mei-yung Leung Ibukun Famakin, Timothy Kwok. Relationships between indoor facilities management components and elderly people's quality of life: A study of private domestic buildings [M]. Habitat International, 2017. 